\title{
Does grip strength correlate with rotator cuff strength in patients with atraumatic shoulder instability?
}

Ruqayyah Turabi ${ }^{*}$ (D), lan Horsely ${ }^{2}$, Helen Birch ${ }^{3}$ and Anju Jaggi ${ }^{4}$

\begin{abstract}
Aim: To investigate if there is a correlation between grip strength (GS) and rotator cuff (RC) strength in patients with atraumatic shoulder instability (ASI) and to compare the relationship between these two measures with that previously published for a healthy population. Moreover, to determine if testing GS could be incorporated as a surrogate clinical assessment for RC strength in these patients.
\end{abstract}

Methods: A total of 20 subjects with ASI were included. Out of the 20 patients, eight presented with bilateral instability, which constituted a total of 28 atraumatic unstable shoulders $(N=28)$. GS was measured using a Jamar handdynamometer. External rotation (ER) and internal rotation (IR) strength was tested in inner and outer ranges using a hand-held dynamometer (HHD). Pearson's correlation test was computed to investigate the relationship. Multiple linear regression was conducted to predict GS based on RC strength.

Results: Significant and strong positive correlations were found between GS and inner-range $\operatorname{IR}(r=0.764, P<0.001)$, inner-range $\mathrm{ER}(r=0.611, P=0.001)$, outer-range $\operatorname{IR}(r=0.817, P<0.001)$, and outer-range $\mathrm{ER}(r=0.736, P<0.001)$. A significant regression equation was found $(F(4,23)=13.254, P<0.001)$, with an $R^{2}$ of 0.697 indicating that $R C$ strength explained $69.7 \%$ of the variance in GS.

Conclusions: The results support the hypothesis showing that GS is strongly associated with RC strength in ASI patients. The simplicity of handgrip testing allows it to be used in clinical scenarios where sophisticated assessment tools are not available. GS is a convenient means to monitor patient progress during shoulder rehabilitation programs.

Keywords: Grip strength, Rotator cuff strength, Atraumatic shoulder instability, Rotator cuff, Shoulder instability, Shoulder

\section{Introduction}

Rotator cuff (RC) muscles (supraspinatus, infraspinatus, subscapularis, and teres minor) are considered to be the key dynamic muscles in shoulder stabilization since they contribute significantly to shoulder stability in a number of different ways [1]. They work not only as a dynamic stabilizer but also as static stabilizers because of their orientation and location around the shoulder joint [2].

\footnotetext{
*Correspondence: R-pt@hotmail.com; rturabi@jazanu.edu.sa 1 Jazan University, Jazan 45142, Saudi Arabia

Full list of author information is available at the end of the article
}

While stabilizing the joint, they also allow a wide range of shoulder movement through rotational moments [3]. The $\mathrm{RC}$ muscles are required to counterbalance the forces produced by surrounding muscles and soft tissues [3] and along with scapulothoracic muscles play crucial roles in the functional optimization of the $\mathrm{GHJ}$ to produce efficient movements as they co-contract to stabilize the joint by compressing the humeral head into the glenoid fossa [2]. Rotator cuff muscles form attachments with the joint capsule, which contribute to the increased capsular tension during shoulder active range of motion [2] further stabilizing the joint. 
The shoulder joint is one of the most commonly dislocated joints. The majority of cases (95\%) are due to a traumatic instability, which results from a direct, forceful collision, or falling on outstretched arms [4]. An estimated $5 \%$ of shoulder instability however is classed as atraumatic instability and this refers to a dislocation or subluxation that occurs following a minor injury and/or overuse [5] or sometimes no apparent incident at all. The main etiology of atraumatic instability is poor muscular control and this may also be associated with capsularlabral pathology [6, 7]. Atraumatic shoulder instability is therefore related to muscular imbalances rather than structural causes and this can affect both athletes and non-athletic individuals. Atraumatic shoulder instability results in significant disability not only in sporting pursuits but also in activities of daily living [2].

Rotator cuff weakness is a recognized cause for symptoms in atraumatic shoulder instability patients [8] and improving muscle strength is the focus of rehabilitation programs. Assessing the strength of these muscles is therefore imperative for diagnostic, preventive, and rehabilitative purposes in patients with shoulder diseases [9]. However, in the clinical setting, these muscles are not always objectively measured due to time constraints, patient's limitation, or difficulty in accessing the equipment. Incorporating a new quick and simple assessment test such as testing grip strength to indicate rotator cuff strength would be beneficial.

Grip strength has been widely used in clinical practice for assessing diseases and rehabilitation progression [10]. The handgrip is a physiology-related variable that can be affected by a wide range of factors such as age, gender, and body mass index (BMI) [11]. It is frequently used in rehabilitation centers to compare patient grip strength with normative data or to compare the force generated by dominant and nondominant arms [12]. The handgrip is evaluated not only as an element of hand function but also as an objective index of upper limb functional integrity [11]. For example, grip strength was found to be a predictor for wrist, hand, and forearm performance [13]. Furthermore, grip strength was found to be a predictor for total muscle strength in children and adolescents [14] and upper and lower body strength in racquet players [15]. Grip strength has also been used as an index to assess nutritional status [16].

Several studies have investigated this relationship between grip strength and rotator cuff strength further. Sporrong et al. [17] found positive correlations between handgrip strength and increased activity of rotator cuff muscles in nine subjects using electromyography (EMG). Mandalidis and O'Brien [18] concluded that the isometric grip strength could be used to monitor the isokinetic strength of shoulder stabilizers in eighteen collegiate-level male athletes. In 27 subjects, Horsley et al. [12] suggested using handgrip strength as a monitor for rotator cuff recruitment function. Sathya et al. [11] studied 75 intercollegiate cricket players and concluded that grip strength testing could be used as a predictor for shoulder power. Although these studies reported the presence of the relationship, all were limited to healthy active populations and athletes with asymptomatic shoulders. To the best of our knowledge, no study has investigated the relationship between isometric grip strength and rotator cuff strength in pathological shoulders, especially atraumatic unstable shoulders.

The purpose of this study was to investigate if there is a correlation between grip strength and rotator cuff function in patients with atraumatic shoulder instability and to compare the relationship between these two measures with that previously published for a healthy population.

\section{Materials and methods}

\section{Participants and setting}

Adult patients ( $\geq 18$ years, 13 females and 7 males), with an age range of 18 to 48 years (mean age $\pm \mathrm{SD}=30 \pm$ 9.392) with atraumatic shoulder instability attending outpatient clinics or physiotherapy treatment at a specialist hospital in the UK, were invited to participate in the study. Patients with neurological disorders or wrist and hand pathology were excluded. Patients were given the participant information sheet and the procedure explained to them. If they were willing to participate and fully understood what was involved, they were asked to sign the written informed consent form. The raw data were taken for healthy participants $(N=27$, mean age $19.8 \pm 5.7$ years, range 18 to 23 years) from the study by Horsley et al. [12] and compared to the data collected in this study.

\section{Instrumentation}

Grip strength was measured using a calibrated Jamar Hydraulic Hand Dynamometer (Model 60440, Sammons Preston, Bolingbrook, Illinois). The dynamometer is the most widely used method in the literature and it is considered to be the gold standard for measuring handgrip strength [19]. The excellent intra-rater and inter-rater reliability, as well as the validity of Jamar hydraulic hand dynamometer for measuring handgrip strength have been reported in several studies [20-24].

Shoulder range of motion (ROM) was measured in degrees using a universal plastic goniometer (EZ Read Jamar Goniometer, Patterson Medical, Warrenville, Illinois). A hand-held dynamometer (HHD) (Manual Muscle Tester, model 01163, Lafayette Instruments Company, Lafayette, Indiana, USA) was used to measure the isometric strength of shoulder external and internal 
rotation. The readings from both the Jamar hydraulic dynamometer and the hand-held dynamometer were taken in kilograms.

\section{Grip strength assessment}

Grip strength was measured with the patient in a sitting position (with $90^{\circ}$ knee flexion and the feet in contact with the floor) and with the arm in a neutral position with $90^{\circ}$ elbow flexion (Fig. 1). This position is recommended by the American Society of Hand Therapists (ASHT) to avoid unwanted compensation or overflow of impulses [25]. The patient was asked to squeeze as hard as he/she could and then to relax for about $30 \mathrm{~s}$ before taking the next measurement to allow sufficient recovery time between contractions and to avoid muscle fatigue [12]. The measures were taken three times, and the highest score was taken for statistical analysis [26].

\section{Shoulder range of motion and isometric strength assessment}

Patients lay supine with hips flexed at $45^{\circ}$ and shoulder of measurement abducted to $90^{\circ}$, or as close to $90^{\circ}$ as tolerated with no stabilization. Active range of motion (ROM) in external rotation (ER) and internal rotation (IR) was measured in degrees with a universal goniometer. Following ROM measurement, ER and IR isometric strength in the inner and outer range were measured in kilograms using a hand-held dynamometer (HHD) (Fig. 2). The patient position and the measurement procedure used in this study were similar to that used in previous studies $[27,28]$. Universal goniometer is portable, easy to use and inexpensive; moreover, it has an excellent inter-rater and intera-rater reliability of when assessing upper extremity ROM [29]. HHD has shown an excellent inter-rater and intra-rater reliability in testing shoulder strength [9].

\section{Statistical analysis}

Statistical Package for the Social Sciences (SPSS) for Windows version 25.0 was used (SPSS, Chicago, IL, USA). The means and standard deviations (SD) were calculated for all variables of interest: grip strength in kilograms, the range of motion of the ER and IR in degrees, and the isometric shoulder ER and IR strength in kilograms.

Data were found to be normally distributed and therefore a Pearson's correlation test was used to investigate the association between grip strength and rotator cuff strength in the four different ranges (inner-range IR, inner-range ER, outer-range IR, and outer-range ER). A multiple linear regression analysis was conducted to predict grip strength based on rotator cuff strength. Rotator cuff strength (in all the ranges) served as the predictor variable, and the grip strength served as a criterion variable. For further analysis, a paired $t$ test was carried out

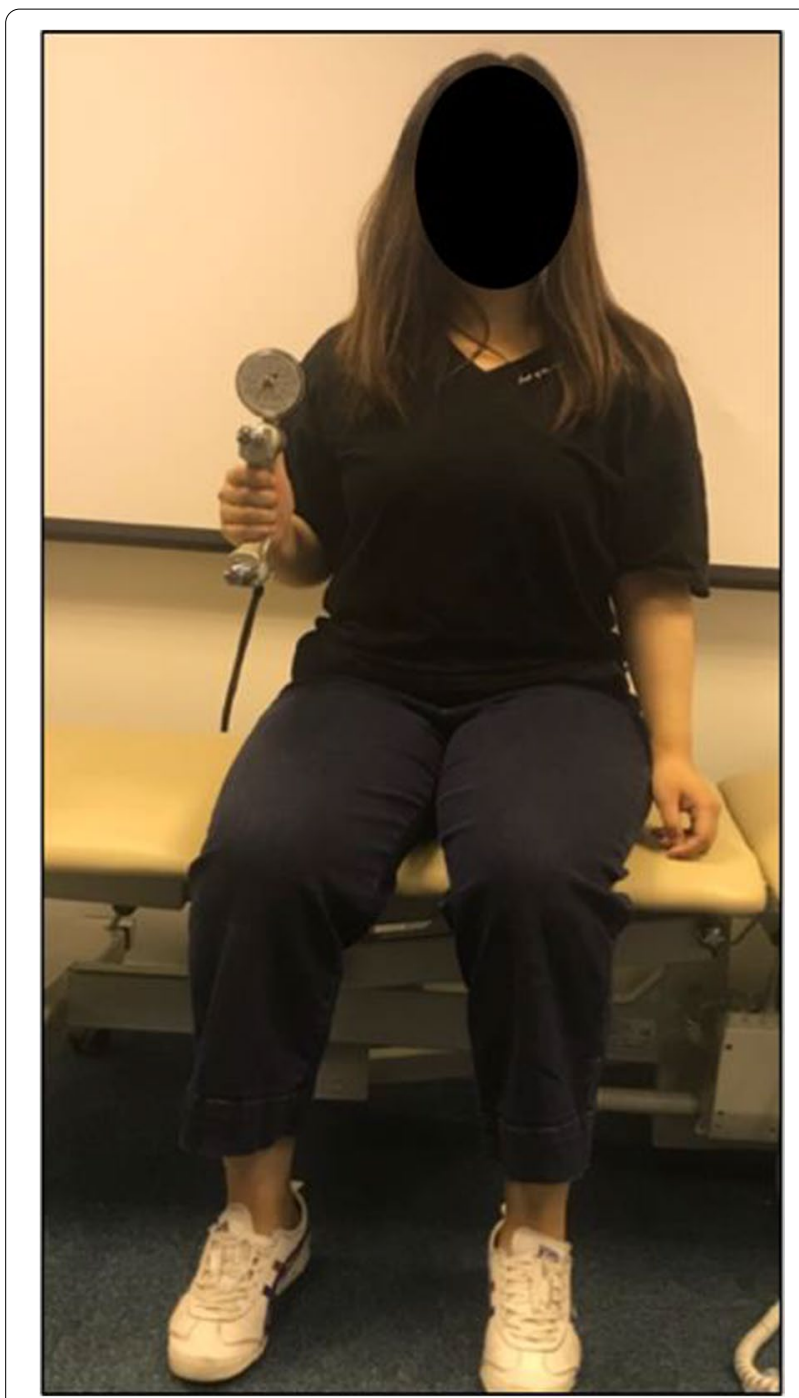

Fig. 1 The subject position while measuring grip strength

to compare external and internal rotator strength in the inner and outer range. Significance level was set at $p \leq$ 0.05 . To compare the relationship between grip strength and rotator cuff strength with that of healthy subjects, a plot of external rotation strength against grip strength was overlaid with data from the healthy participants. Statistical comparison of these data was deemed inappropriate as the measurements were made under different conditions.

\section{Results \\ Descriptive statistics}

A total of 20 patients with atraumatic shoulder instability participated in this study. Out of the 20 subjects, eight patients presented with bilateral instability, which constituted a total of 28 atraumatic unstable shoulders $(N=$ 

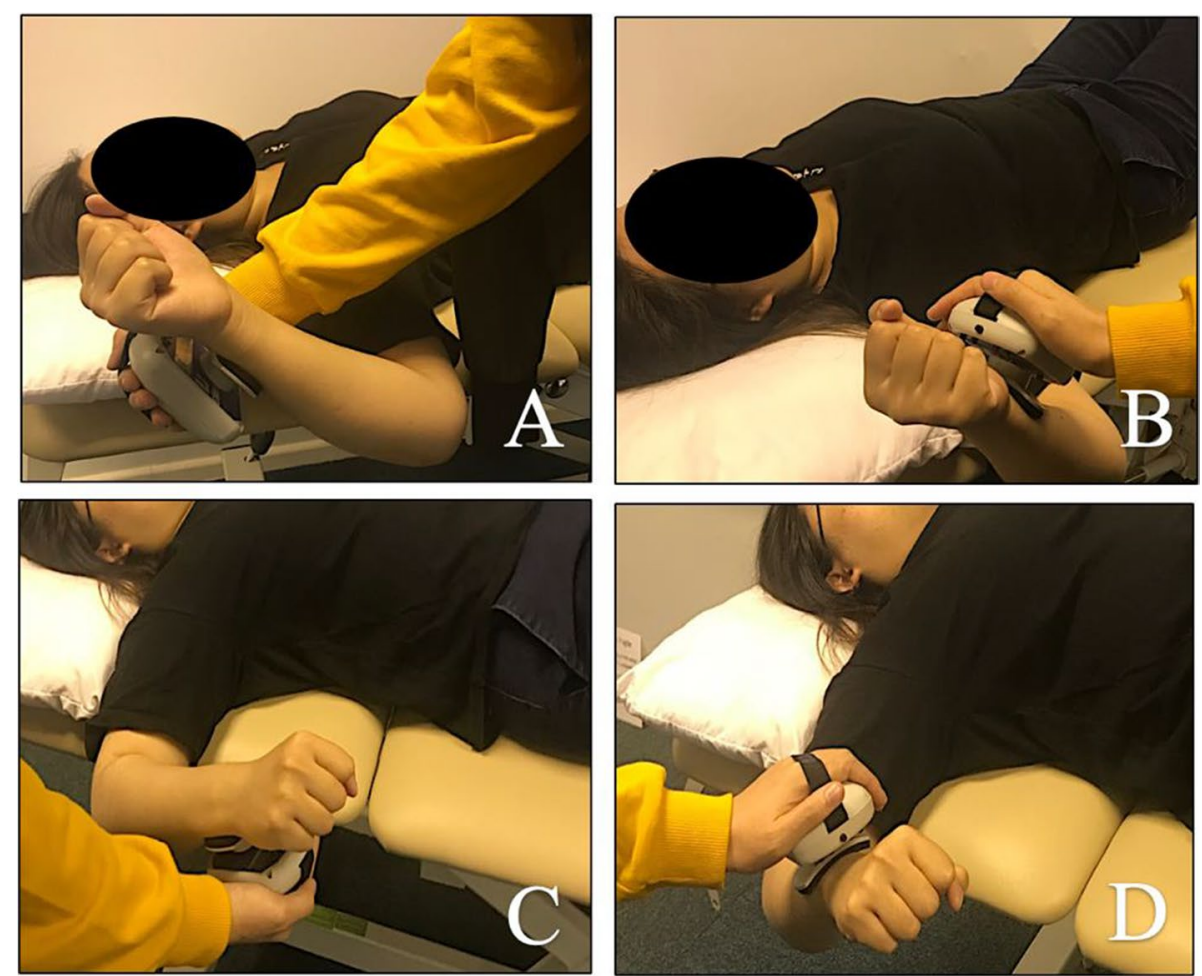

Fig. 2 Subject's position while applying the resistance by the HHD when assessing the isometric rotator cuff strength. A External rotation (inner range). B Internal rotation (outer range). C Internal rotation (inner range). D External rotation (outer range)

28). In this study, $65 \%$ of the patients were females $(N=$ $13)$, and $35 \%$ were males $(N=7)$.

The mean and the standard deviation for grip strength, isometric inner range internal and external rotations, isometric outer range external and internal rotations, and the ROM of external and internal rotation for patient with atraumatic shoulder instability are given in Table 1 . Table 2 shows the mean and SD for healthy participants taken from Horsley et al. [12].

\section{Rotator cuff isometric strength}

The paired $t$ test indicated no significant difference between the strength of the inner-range IR and outerrange IR, and no significant difference between the strength of the outer-range IR and outer-range ER. The outer-range ER was significantly stronger than the innerrange ER $(P=0.001)$. A significant difference was found between the strength of the inner-range ER and innerrange IR $(P=0.001)$.

\section{Relationship between grip strength and shoulder strength} When using Pearson's correlation test $(r)$, a number of significant and positive correlations were observed between grip strength and rotator cuff strength (twotailed) (Table 3). A significant and strong positive correlation was found between grip strength and shoulder internal rotation in the inner range $(r=0.764, P<0.001)$. A significant and strong positive correlation was found between grip strength and shoulder external rotation in the inner range $(r=0.611, P=0.001)$. A significant and

Table 1 Presentation of the mean and SD for grip strength, isometric inner range internal and external rotations, isometric outer range external and internal rotations, and the ROM of external and internal rotation for patient with atraumatic shoulder instability. $\mathrm{N}$ $=20$

Grip strength (kg) IR inner range (kg) ER inner range (kg) IR outer range (kg) ER outer range (kg) IR ROM ( $\left(^{\circ}\right)$ ER ROM ( $\left(^{\circ}\right)$

\begin{tabular}{lllllll}
\hline Mean and SD & $30 \pm 13.48$ & $5.7 \pm 2.5$ & $4.7 \pm 1.8$ & $6.06 \pm 2.7$ & $6.05 \pm 2.4$ & $63 \pm 19.9$ \\
\hline
\end{tabular}


Table 2 Presentation of the mean and SD for grip strength and isometric strength external rotations for healthy participants $(n=$ 27)

\begin{tabular}{lll}
\hline & Grip strength $\mathbf{( k g )}$ & External rotation $\mathbf{( k g )}$ \\
\hline Mean and SD & $36 \pm 9.4$ & $5.59 \pm 1.7$ \\
\hline
\end{tabular}

very strong positive correlation was found between grip

Table 3 Pearson correlation coefficients $(r)$ between grip strength and rotator cuff strength of the internal and external rotation in the inner and outer range $(N=28)$

\begin{tabular}{|c|c|c|c|c|}
\hline & $\begin{array}{l}\text { Isometric } \\
\text { IR (inner } \\
\text { range) }\end{array}$ & $\begin{array}{l}\text { Isometric } \\
\text { ER (inner } \\
\text { range) }\end{array}$ & $\begin{array}{l}\text { Isometric } \\
\text { IR (outer } \\
\text { range) }\end{array}$ & $\begin{array}{l}\text { Isometric ER } \\
\text { (outer range) }\end{array}$ \\
\hline $\begin{array}{l}\text { rip } \\
\text { rength }\end{array}$ & $\begin{array}{l}r(28)= \\
.746^{* *}\end{array}$ & $\begin{array}{l}r(28)= \\
.611^{* *}\end{array}$ & $\begin{array}{l}r(28)= \\
.817^{* *}\end{array}$ & $r(28)=$ \\
\hline
\end{tabular}

**P $\leq 0.001$ (2-tailed)

strength and shoulder internal rotation in the outer range $(r=0.817, P<0.001)$. A significant and strong positive correlation was found between grip strength and shoulder external rotation in the outer range $(r=0.736, P<$ 0.001). Therefore, the null hypothesis of the absence of the correlation between grip strength and rotator cuff strength is rejected.

\section{Regression analysis}

A multiple linear regression was computed to predict the grip strength based on rotator cuff strength (IR and ER in the inner and outer range). A significant regression equation was found $(F(4,23)=13.254, P<0.001)$, with an $R^{2}$ of 0.697 indicating that $69.7 \%$ of the variance of grip strength could be explained by rotator cuff strength (Fig. 3). While the internal rotation in the outer range contributed significantly to the grip strength $(B=$ 2.992, $P<0.05)$, the internal rotation in the inner range ( $B=0.171, P=0.898)$, the external rotation in the inner range $(B=1.249, P=0.295)$, and the external rotation in the outer range $(B=0.506, P=0.681)$ did not. The final predictive model was: Grip strength $=2.064+(0.171 \times$ inner-range IR $)+(1.249 \times$ inner-range ER $)+(2.992 \times$ outer-range IR $)+(0.506 \times$ outer-range ER $)$.

\section{Atraumatic shoulder instability versus healthy shoulders}

When comparing the raw data of healthy participants from the study by Horsley et al. [12] to the data collected in this study, unpaired $t$ test showed no significant difference in grip strength $(P=0.068)$ or external

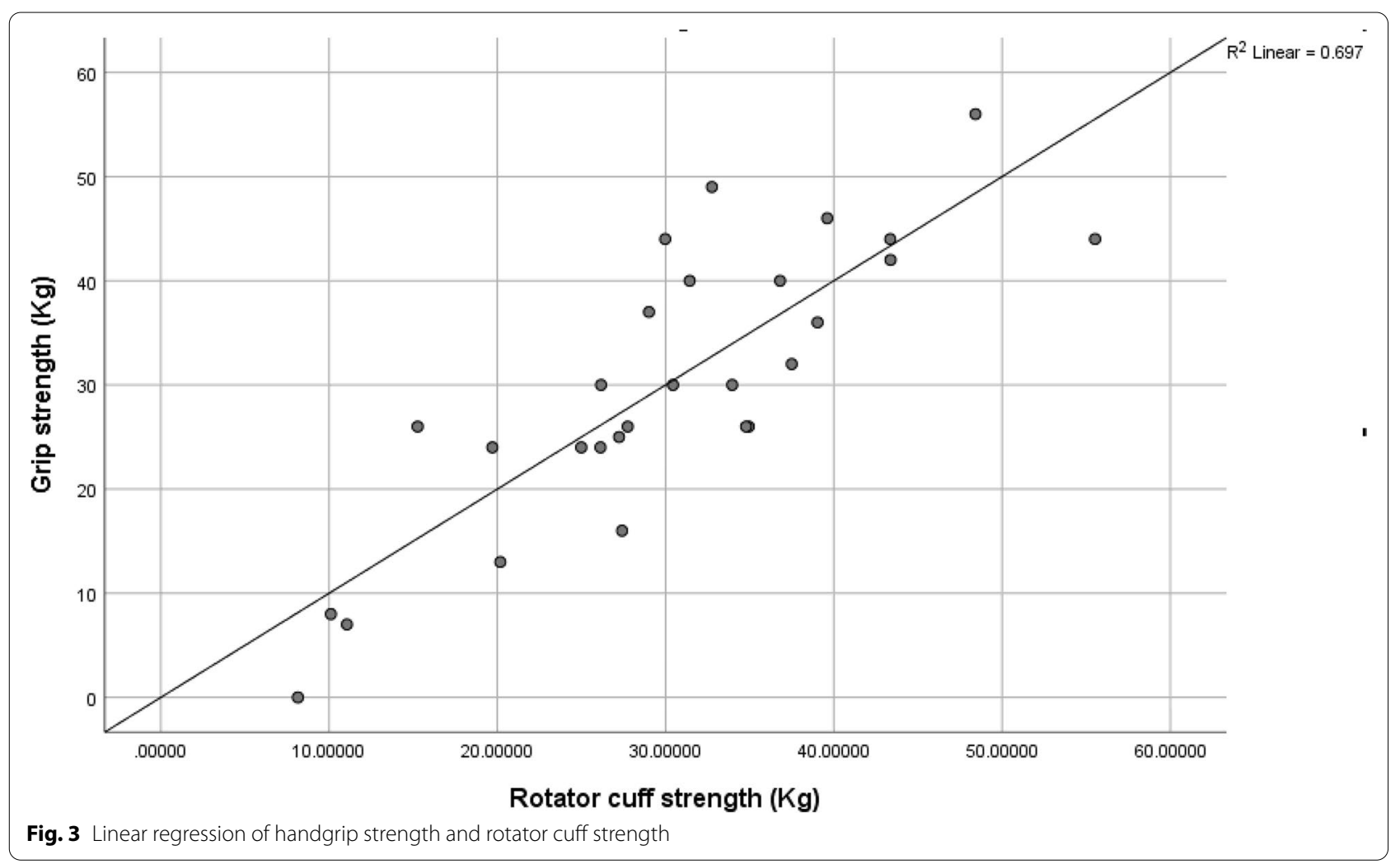


rotation isometric strength $(P=0.084)$ between healthy participants and ASI patients. Moreover, the relationship between grip strength and RC external rotation strength appears to be similar (Fig. 4). Interestingly, although the ASI group had some of the lowest strength values, the majority of values overlaid those of the healthy population.

\section{Discussion}

The primary purpose of this study was to investigate if there is a correlation between grip strength and rotator cuff strength in atraumatic shoulder instability patients. Grip strength and rotator cuff strength were examined isometrically across 20 patients with 28 unstable shoulders. The results of this study support the hypothesis showing strong positive correlations between grip strength and rotator cuff strength in the inner and outer range.

The scores of grip strength were compared with the normative reference values of the healthy population. In the literature, grip strength was found to be significantly higher with the elbow in extension or during standing than with elbow flexion due to the overflow of impulses [25]; therefore, we focused only on the articles that involved Jamar hydraulic hand dynamometer as an outcome measure and the same position as in our study (sitting with the arm in a neutral position and $90^{\circ}$ elbow flexion). In line with many studies, this study found that males have a stronger grip strength as well as internal and external rotation strength when compared with females of the same age group [23, 30].

The scores of shoulder external and internal rotation strength were also compared against the normative data for healthy population. There was no significant difference between the results of healthy active population and patients with atraumatic shoulder instability.

In rehabilitation, it is widely accepted that effective muscle action on distal joints can be achieved when proximal joints are efficiently stabilized by the surrounding structures [18]. Therefore, the link between proximal stability and distal mobility could explain the relationship between handgrip strength and rotator cuff strength [31]. Several interventional studies supported this link and reported a significant increase in grip strength with increased shoulder stability [31, 32].

Since the correlation has been established, a multiple linear regression analysis was conducted to investigate if handgrip strength can be predicted based on rotator

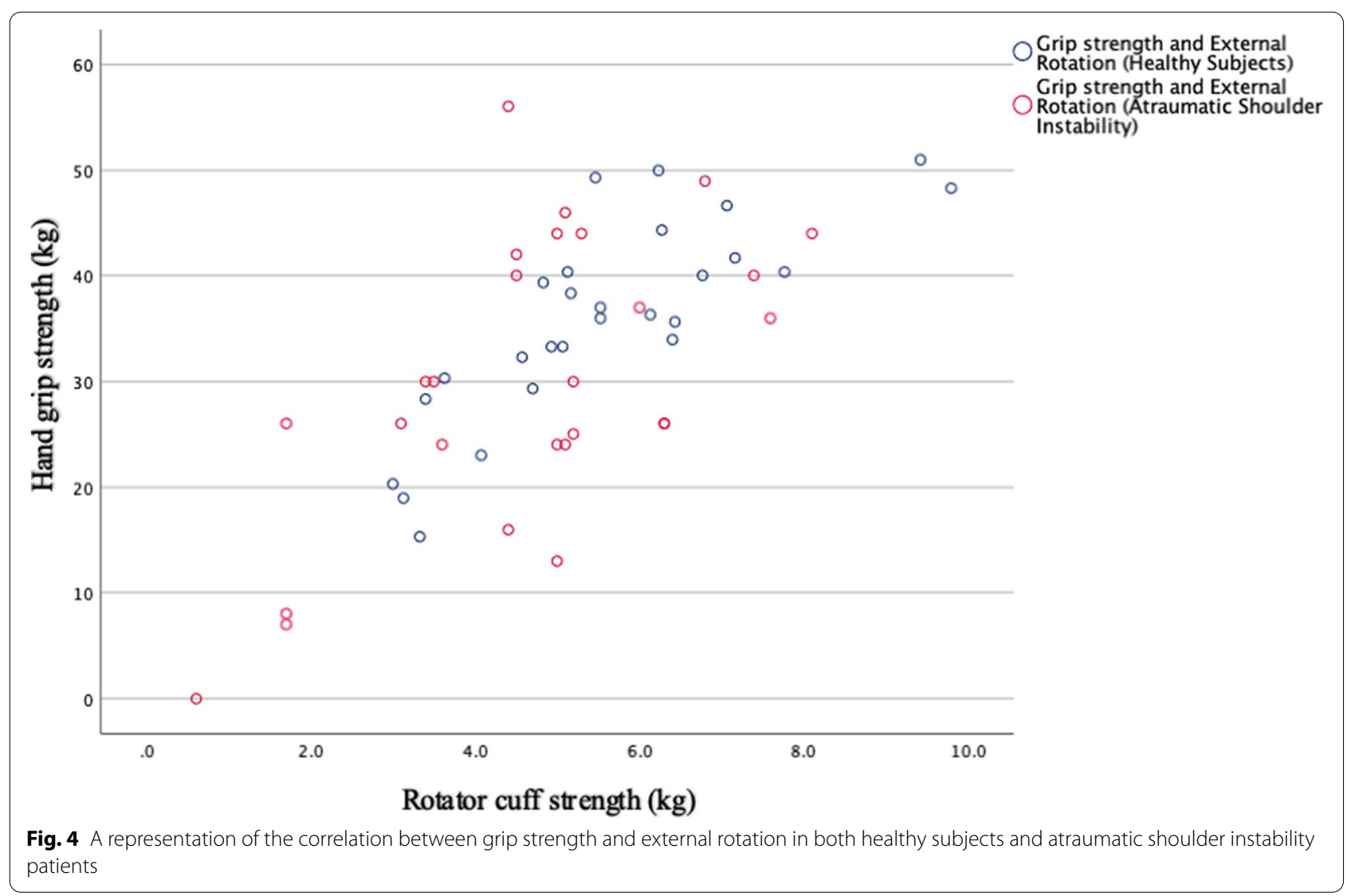


cuff strength and was found to be significant. The results indicated that $69.7 \%$ of the variance in the grip strength is explained by rotator cuff strength. Mandalidis and O'Brien [18] suggested that the relationship between the handgrip and rotator cuff could be explained based on the overflow principle, which is mediated by the neural circuits in the central nervous system (CNS) leading to the co-activation of the agonists and synergists muscle groups that are responsible for a specific task. The presence of the co-activation was supported by EMG studies, which reported that gripping increases the activities within some muscles around the shoulder joint and decreases others [17, 33]. Sporrong et al. [17] found that rotator cuff muscles are the most activated by handgrip. Therefore, these findings suggest that grip strength could be used as an indicator of rotator cuff strength.

The regression findings also indicated that the outerrange IR strength contributed significantly to the grip strength, and the grip strength increased $2.2992 \mathrm{~kg}$ for each $1 \mathrm{~kg}$ of the outer-range IR strength. Anatomically, when the origin is fixed, latissimus dorsi and pectoralis major both act to adduct and internally rotate the humerus (along with subscapularis) [34]. Since it is widely accepted that hand flexors, shoulder adductors, and internal rotators are among the upper limb synergists; we could speculate that the co-activation of these synergistic muscles might be a reason behind the increased contribution of internal rotators toward grip strength.

Despite the difference with regards to the chosen sample (healthy population), the examined muscle groups (external rotators), and the mode of examination (isometric or isokinetic), the positive correlation between grip strength and rotator cuff strength in this study is in agreement with those reported in the literature $[12,18]$. Isometric grip strength testing is simple, easy to perform, less time consuming than measuring shoulder internal and external rotation, and strongly associated with the rotator cuff strength; therefore, it could be used as an outcome measure to monitor the patient's progression during shoulder rehabilitation programs. The simplicity of handgrip measurement allows it to be used in clinical scenarios where sophisticated assessment tools are not available.

Special tests such as belly-press as well as infraspinatus retraction tests are used to examine the rotator cuff muscles in their inner range [35]; nonetheless, it is necessary to examine these muscles in the full range including the outer range [36]. Therefore, this study investigated the isometric rotator cuff strength in both inner and outer ranges. The findings indicated that both the ER and IR were stronger in the outer range than in the inner range. The increased strength in the outer range could be explained by the length-tension relationship.

The length-tension relationship is related to the sarcomere and the sliding filament theory. It states that the maximum force production happens when the muscle is at resting length where they are not in extreme shortened or lengthened position [3]. It is widely accepted that the normal ROM of internal and external rotation (from $90^{\circ}$ abduction and $90^{\circ}$ elbow flexion) is between 80 and $90^{\circ}$ [37]. Since the patients had instability, they were not able to bring their shoulders to maximum internal and external rotation. This enables muscles to stay in their resting position contributing to maximum force production. When the muscle stretches beyond its resting length, the actin slides apart from the myosin where the passive tension (from the Titin protein (Connectin)) increases and the active tension decreases, contributing to decreased force production [38].

The weakness of the external rotators in recurrent anterior shoulder instability patients was reported in different studies [39, 40]. Similarly, the results indicated that the inner-range ER is significantly weaker than innerrange IR and the outer-range ER. A possible reason for the weakness is the patient's apprehension to move their arms toward the external rotation from $90^{\circ}$ abduction since this position is the most common cause of anterior dislocation [40].

This study has some limitations. The direction of instability and factors such as weight and height were not taken into consideration. This study was not able to investigate the correlation between grip strength and rotator cuff strength pre- and post-intervention.

Future studies are suggested to investigate the relationship between grip strength and rotator cuff strength while considering the direction of shoulder instability and to investigate the correlation between the strength of handgrip and rotator cuff before and after shoulder rehabilitation in this group.

\section{Conclusion}

The results of this study demonstrate that grip strength is strongly associated with rotator cuff strength in patients with ASI. Isometric handgrip strength is quick and easy to test, and therefore could provide a convenient means to provide an objective measure of rotator cuff strength; however, low strength alone is not an indicator of ASI.

\section{Authors' contributions}

Ruqayyah Turabi carried out the study as part of Masters Project, collected the data, analyzed the data, and wrote it. lan Horsely provided us with data of healthy population to compare our data with. Helen Birch supervised the study. Anju Jaggi supervised the study and provided us with the patients to collect the data from. The authors read and approved the final manuscript. 


\section{Funding}

This study was undertaken as an MSc research project on the Physical Therapy in Musculoskeletal Healthcare and Rehabilitation MSC at UCL and supported by bench fees for the MSc program.

\section{Availability of data and materials}

The data that support the findings of this study are available from the corresponding author upon reasonable request.

\section{Declarations}

\section{Ethics approval and consent to participate}

This study was conducted in accordance with the research governance framework, EU and UK legislation, and the applicable UK acts. It was approved by London-Stanmore Research Ethics Committee and by Health Research Authority (HRA) and Health and Care Research Wales (HCRW) with a reference number of (18/LO/0901). If patients were happy to participate and fully understood what was involved, they were asked to sign the participant consent form. All queries were answered prior to the measurement, and the patients were given a copy of their signed consent form.

\section{Consent for publication}

We confirm that all authors have approved the manuscript and agree with its submission to this journal.

\section{Competing interests}

The authors declare that they have no competing interests.

\section{Author details}

${ }^{1}$ Jazan University, Jazan 45142, Saudi Arabia. ${ }^{2}$ English Institute of Sport, Manchester M11 3BS, UK. ${ }^{3}$ University College London, London WC1E 6BT, UK. ${ }^{4}$ Royal National Orthopaedic Hospital, Stanmore HA7 4LP, UK.

Received: 3 September 2021 Accepted: 14 November 2021

Published online: 12 January 2022

\section{References}

1. Dark A, Ginn KA, Halaki M. Shoulder muscle recruitment patterns during commonly used rotator cuff exercises: an electromyographic study. Phys Ther. 2007;87(8):1039-46.

2. Warth RJ, Millett PJ. Physical examination of the shoulder: Springer; 2015.

3. Longo UG, Berton A, Papapietro N, Maffulli N, Denaro V. Biomechanics of the rotator cuff: European perspective. Rotator Cuff Tear. 2012;57:10-7.

4. Bateman M, Jaiswal A, Tambe AA. Diagnosis and management of atraumatic shoulder instability. J Arthroscopy Joint Surg. 2018;5(2):79-85.

5. O'Kane JW, Toresdahl BG. The evidenced-based shoulder evaluation. Curr Sports Med Rep. 2014;13(5):307-13.

6. Jaggi A, Lambert S. Rehabilitation for shoulder instability. Br J Sports Med. 2010;44(5):333-40.

7. Lewis A, Kitamura T, Bayley JI. (ii) The classification of shoulder instability: new light through old windows! Curr Orthop. 2004;18(2):97-108.

8. Wright AC, Monga P. Diagnosing shoulder instability. J Arthroscopy Joint Surg. 2018;5(2):67-70

9. Cools AM, De Wilde L, Van Tongel A, Ceyssens C, Ryckewaert R, Cambier DC. Measuring shoulder external and internal rotation strength and range of motion: comprehensive intra-rater and interrater reliability study of several testing protocols. J Shoulder Elb Surg. 2014;23(10):1454-61.

10. Reuter SE, Massy-Westropp N, Evans AM. Reliability and validity of indices of hand-grip strength and endurance. Aust Occup Ther J. 2011;58(2):82-7.

11. Sathya P, Kadhiravan V, Ramakrishnan K, Ghodake A. Association between hand grip strength and shoulder power in intercollegiate cricket players. Int J Innov Res Sci Eng Tech. 2016;5:3085-91.

12. Horsley I, Herrington L, Hoyle R, Prescott E, Bellamy N. Do changes in hand grip strength correlate with shoulder rotator cuff function? Should Elb. 2016;8(2):124-9.
13. Richards LG, Olson B, Palmiter-Thomas P. How forearm position affects grip strength. Am J Occup Ther. 1996;50(2):133-8.

14. Wind $A E$, Takken $T$, Helders PJ, Engelbert $\mathrm{RH}$. Is grip strength a predictor for total muscle strength in healthy children, adolescents, and young adults? Eur J Pediatr. 2010 Mar:169(3):281-7.

15. Mohamed MA, Kadir ZA, Yusof SM, Mazaulan M, Adnan MA. Relationship between handgrip strength on muscular strength among racquet sport athletes. In: I International Colloquium on Sports Science, Exercise, Engineering and Technology; 2014. p. 259-66. Springer, Singapore.

16. Pieterse S, Manandhar M, Ismail S. The association between nutritional status and handgrip strength in older Rwandan refugees. European journal of clinical nutrition. 2002;56(10):933-9.

17. Sporrong H, Palmerud G, Herberts P. Hand grip increases shoulder muscle activity: an EMG analysis with static handcontractions in 9 subjects. Acta Orthop Scand. 1996;67(5):485-90.

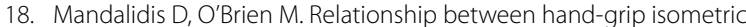
strength and isokinetic moment data of the shoulder stabilisers. J Bodywork Movement Ther. 2010;14(1):19-26.

19. Roberts HC, Denison HJ, Martin HJ, Patel HP, Syddall H, Cooper C, et al. A review of the measurement of grip strength in clinical and epidemiological studies: towards a standardised approach. Age Ageing 2011;40(4):423-9.

20. Beaton DE, O'Driscoll SW, Richards RR. Grip strength testing using the BTE work simulator and the Jamar dynamometer: a comparative study. J Hand Surg. 1995;20(2):293-8.

21. Hamilton A, Balnave R, Adams R. Grip strength testing reliability. J Hand Ther. 1994;7(3):163-70.

22. Mathiowetz V, Weber K, Volland G, Kashman N. Reliability and validity of grip and pinch strength evaluations. J Hand Surg. 1984;9(2):222-6.

23. Peolsson A, Hedlund R, Öberg B. Intra-and inter-tester reliability and reference values for hand strength. J Rehabil Med. 2001;33(1):36-41.

24. Mathiowetz $V$, Wiemer DM, Federman SM. Grip and pinch strength: norms for 6-to 19-year-olds. Am J Occup Ther. 1986;40(10):705-11.

25. Su CY, Lin JH, Chien TH, Cheng KF, Sung YT. Grip strength in different positions of elbow and shoulder. Arch Phys Med Rehabil. 1994;75(7):812-5.

26. Ekstrand $\mathrm{E}$, Lexell J, Brogårdh C. Grip strength is a representative measure of muscle weakness in the upper extremity after stroke. Top Stroke Rehabil. 2016:23(6):400-5.

27. Awan R, Smith J, Boon AJ. Measuring shoulder internal rotation range of motion: a comparison of 3 techniques. Arch Phys Med Rehabil. 2002;83(9):1229-34

28. Ellenbecker TS, Roetert EP, Piorkowski PA, Schulz DA. Glenohumeral joint internal and external rotation range of motion in elite junior tennis players. J Orthop Sports Phys Ther. 1996 Dec;24(6):336-41.

29. Kolber MJ, Hanney WJ. The reliability and concurrent validity of shoulder mobility measurements using a digital inclinometer and goniometer: a technical report. Int J Sports Phys Ther. 2012;7(3):306.

30. McKay MJ, Baldwin JN, Ferreira P, Simic M, Vanicek N, Burns J. 1000 Norms Project Consortium. Normative reference values for strength and flexibility of 1,000 children and adults. Neurology. 2017;88(1):36-43.

31. Kachanathu SJ, Zedan AM, Hafez AR, Alodaibi FA, Alenazi AM, Nuhmani S. Effect of shoulder stability exercises on hand grip strength in patients with shoulder impingement syndrome Somatosens Mot Res. 2019:36(2):97-101.

32. Shim J, Park M, Lee S, Lee M, Kim H. The effects of shoulder stabilization exercise and shoulder isometric resistance exercise on shoulder stability and hand function. J Phys Ther Sci. 2010;22(3):227-32.

33. Antony NT, Keir PJ. Effects of posture, movement and hand load on shoulder muscle activity. J Electromyogr Kinesiol. 2010;20(2):191-8.

34. Jaggi A, Noorani A, Malone A, Cowan J, Lambert S, Bayley I. Muscle activation patterns in patients with recurrent shoulder instability. Inte J Shoulder Surg. 2012;6(4):101.

35. Merolla G, De Santis E, Campi F, Paladini P, Porcellini G. Infraspinatus scapular retraction test: a reliable and practical method to assess infraspinatus strength in overhead athletes with scapular dyskinesis. J Orthop Traumatol. 2010;11(2):105-10.

36. Jaggi A, Alexander S. Suppl-6, M13: Rehabilitation for shoulder instabilitycurrent approaches. Open Orthop J. 2017;11:957.

37. Lawry GV, Kreder HJ, Hawker G, Jerome D. Fam's musculoskeletal examination and joint injection techniques e-book: expert consult. Elsevier Health Sciences; 2010. 
38. Lieber RL, Bodine-Fowler SC. Skeletal muscle mechanics: implications for rehabilitation. Phys Ther. 1993;73(12):844-56.

39. Saccol MF, Zanca GG, Ejnisman B, de Mello MT, Mattiello SM. Shoulder rotator strength and torque steadiness in athletes with anterior shoulder instability or SLAP lesion. J Sci Med Sport. 2014;17(5):463-8.

40. Sadeghifar A, Ilka S, Dashtbani H, Sahebozamani M. A comparison of glenohumeral internal and external range of motion and rotation strength in healthy and individuals with recurrent anterior instability. Arch Bone Joint Surg. 2014;2(3):215.

\section{Publisher's Note}

Springer Nature remains neutral with regard to jurisdictional claims in published maps and institutional affiliations.

\section{Submit your manuscript to a SpringerOpen ${ }^{\circ}$ journal and benefit from:}

- Convenient online submission

- Rigorous peer review

- Open access: articles freely available online

- High visibility within the field

- Retaining the copyright to your article

Submit your next manuscript at $>$ springeropen.com 